- Entomologica Fennica. 8 January 1998

\title{
Two new Elachista species (Lepidoptera, Elachistidae) from the Polar Urals region, Russia
}

\author{
Lauri Kaila
}

Kaila, L. 1998: Two new Elachista species (Lepidoptera, Elachistidae) from the Polar Urals region, Russia. — Entomol. Fennica 8: 219-223.

Two new species of Elachista (Lepidoptera, Elachistidae) are described on the basis of material collected from the Sob River valley in the Polar Urals, and in the vicinity of Labytnangi on the shores of the Ob River: Elachista jaskai sp. n., which is assigned to the Elachista bifasciella group, and Elachista ripula sp. n., related to Elachista triatomea in the Elachista argentella group. E. ripula sp. n. is also reported from northern Finland. Diagnostic characteristics for the new species are given. Photographs of the habitus and genitalia are provided for the new species.

Lauri Kaila, Finnish Museum of Natural History, P.O. Box 17, FIN-00014 University of Helsinki, Finland

Received 8 January 1997, accepted 27 April 1997

\section{Introduction}

Little information is available concerning the Lepidoptera of the Polar Ural mountain region, although the region forms one of the borders of Europe. Most of the available literature only considers butterflies, while other Lepidopteran groups have almost entirely been overlooked. Nearly no information on the Microlepidoptera of the region is available.

In the summer of 1994 a Finnish-Russian entomological expedition was made to the Polar Urals. The expedition yielded a considerable amount of lepidopteran material, all of which will be published elsewhere (J. Jalava \& J. Kullberg, pers. comm.). The material also contains two new species of Elachista which are described here.

The material was collected from the northern parts of the Ural mountains, and on western shores of the river $\mathrm{Ob}$. Only a brief description of the collecting sites is presented here. More detailed information will be given elsewhere (J. Jalava \& J. Kullberg, in prep.).
Krasnyi Kamen, the easternmost slopes of the Urals, $66^{\circ} 55^{\prime} \mathrm{N}, 65^{\circ} 10^{\prime} \mathrm{E}$ in the Sob river valley, $200 \mathrm{~m}$; mainly bogs, birch and larch forests, and sandy riverside meadows of Sob.

The western shores of the Ob river, $8 \mathrm{~km} \mathrm{~N}$ from Labytnangi $66^{\circ} 42^{\prime} \mathrm{N}, 6635 \mathrm{E}$ at altitude of $80 \mathrm{~m}$ shore meadows and larch forests.

The terminology follows Traugott-Olsen and Nielsen (1977).

\section{Elachista jaskai sp. n.}

Figs. 1, 2, 2a, 2b, 3

Type material. - Holotype ơ: Russia, Polar Ural 66 55 N $65^{\circ} 10^{\prime} \mathrm{E}$, Krasnyi Kamen 400 m, alpine meadow, Malaise trap. 2,-8.vii.1994 Jalava, Kullberg \& Koponen leg. in coll. Zoological Museum, University of Helsinki.

Description. - Labial palpus rather short, mottled leaden grey; second article weakly curved, third article short. Head and neck tufts leaden grey, mottled with slightly darker tips of scales. Antenna short and thick, leaden grey, ventrally weak- 


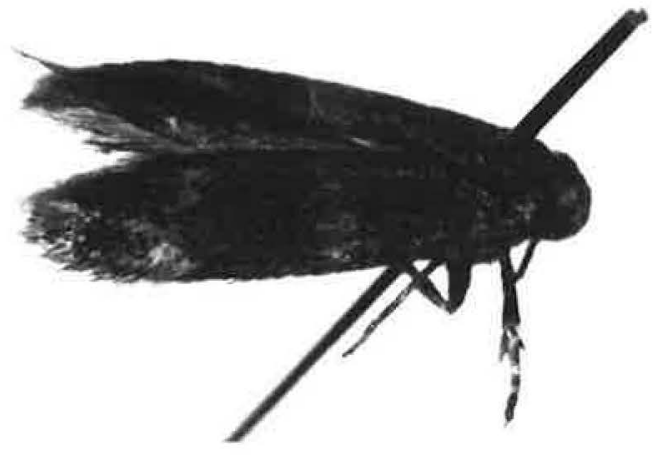

Fig. 1. Elachista jaskai sp. n. m holotype.

ly serrate, distal margins of articles with a few long stiff setae; articles ventrally densely covered with short setae. Patagium, thorax and abdomen mottled dark grey. Legs leaden grey, tibia and tarsal articles with lighter distal rings. Forewing rather broad, ground colour leaden grey, densely mottled with dark grey tips of scales; before middle indistinct bluish grey straight transverse fascia not reaching costa or dorsal margin; in $4 / 5$ of costa triangular outwardly directed bluish grey patch, and smaller rounded spot on opposite side in tornus. Cilia grey, with no cilia line. Hindwing and underside of wings grey. Forewing length $3.4 \mathrm{~mm}$.

Male genitalia: Uncus lobes large, slightly longer than their width, median margin almost straight, distal and lateral margins rounded, ventral surface densely covered with long hair-like

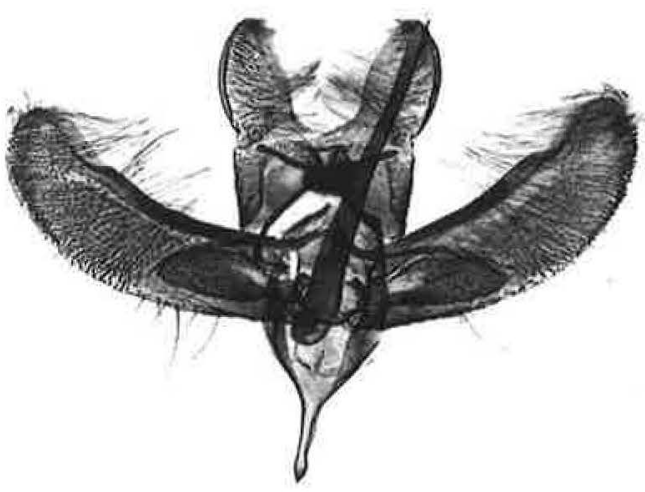

scales; with broad u-shaped indentation between them. Gnathos rounded. Median margin of juxta lobes nearly straight meeting distal margin at obtuse angle; ventral surface weakly truncate with setae. Digitate process extremely large extending to $2 / 5$ of valva, broadest medially, gradually tapering towards blunt apex. Valva broadest beyond middle, costa slightly concave, cucullus somewhat produced towards costa, sacculus evenly curved meeting cucullus without angle. Vinculum with weak median ridge, tapering into very long pointed saccus. Aedeagus relatively small, almost straight, broadest basally, gradually tapering towards apex, with one very small and weakly sclerotized arrow-shaped cornutus.

Diagnosis. - The new species belongs to the Elachista bifasciella group in the classification of Traugott-Olsen and Nielsen (1977). Within the group the new species cannot be placed near any other palearctic species. E. jaskai sp. n. differs by the following characters from all the other described species: The digitate process of male genitalia is extremely large, extending to $2 / 5$ of valva. The saccus is also exceptionally long. The male antenna is short and thick, articles are ventrally slightly serrate and with short cilia; in addition, in the distal margin of each article there are long stiff setae that are not found in any other species known to me. In North America there is a group of undescribed species with similar, even longer ciliation in antenna, although without the stiff setae. According to this ciliation, the new species could be assigned as the single Palearctic representative to the same species complex with the Nearctic taxa. The descriptions of the American species will be published in another context ( $\mathrm{L}$. Kaila, in prep.).
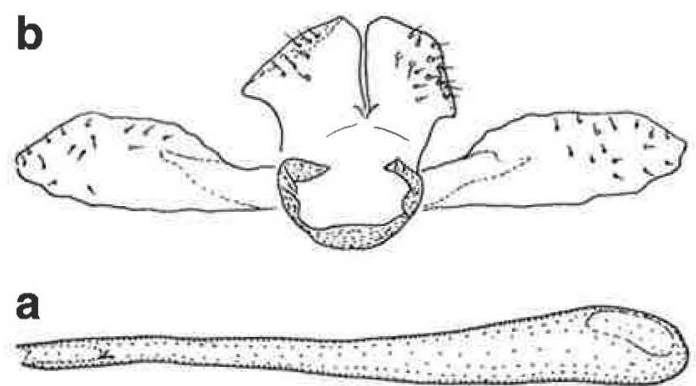

Fig. 2. Male genitalia of Elachista jaskai sp. n. holotype (LK 1949). - a: Aedeagus. - b: Juxta and digitate process. 


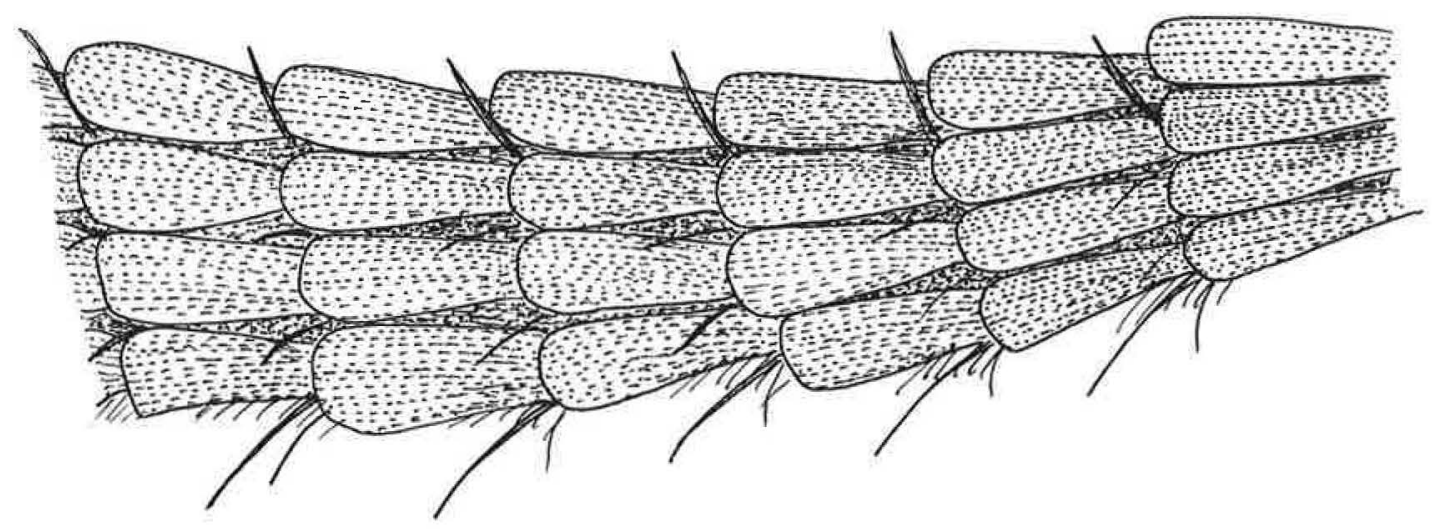

Fig. 3. Male antennal articles of Elachista jaskaisp. n., in lateral view.

\section{Elachista ripula sp. $\mathbf{n}$.}

Figs. 4, 5, 6, 6a, 6b, 7, 7a, 7b, 9

Type material. - Holotype ơ: Russia, Polar Ural $66^{\circ} 55 \mathrm{~N}$ $65^{\circ} 10^{\prime} \mathrm{E}$, Krasnyi Kamen, $200 \mathrm{~m}$, sandy riverside meadow 16.vii.1994 Jalava, Kullberg \& Koponen leg. L. Kaila prep. no. 1367. Paratypes ( $20^{\top} 2$ O): 1 \& with the same collection data as in holotype, 1 \% with the same data except for the collection date 5.vii.1994; $10^{7}$ with the same collection data as in holotype except for the habitat 'peat bog/meadow' and date 7.vii.1994; Russia Ob Delta $66^{\circ} 42^{\prime} \mathrm{N} 66^{\circ} 35^{\circ} \mathrm{E}$, $8 \mathrm{~km}$ N Labytnangi, Ob shore meadows $80 \mathrm{~m}, 11$.vii.1994 $10^{7}$ Jalava, Kullberg \& Koponen leg. (all in the Zoological Museum, University of Helsinki).

Additional material: Finland, Li: Utsjoki, Karigasniemi 7.-8.vii.1983 1 오 E. T. Linnaluoto leg. (Coll. Zoological Museum, University of Turku).

Description. - Labial palpus long curved, white, second article ochreous to greyish brown below. Head and neck tufts white. Scape of antenna white, flagellum unicolorous grey in ơ, in $\$$ weakly annulated with light grey. Patagium and thorax white, weakly dusted with greyish tips of scales. Abdomen silky grey, segments with transverse white bands distally. Legs light grey. Forewing broad, costa in basal $1 / 5$ th grey; ground colour white, irregularly dusted with grey tips of scales especially in distal part of wing; elongate dark brown spot in the middle of wing at fold, and another similar spot at $2 / 3$ rds of wing; in some specimens a third irregular and indistinct spot at 3/4th of dorsal margin. Cilia line dark grey. Cilia basally white, distally grey. Hindwing shining light grey, translucent. Underside of wings grey. Forewing length $4.6-5.4 \mathrm{~mm}$.

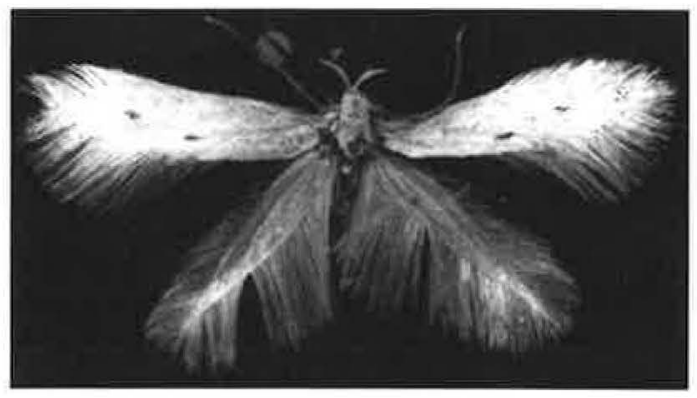

Fig. 4. Elachista ripula sp. n. ơ holotype.

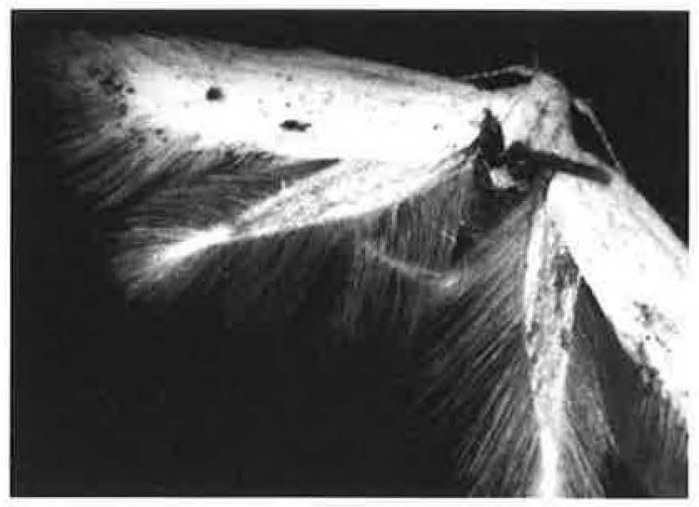

Fig. 5. Elachista ripula sp. n. @ paratype.

Male genitalia: Uncus lobes triangular, apex rounded, with a few small setae along lateral margin. Gnathos rather small, slender, nearly parallel-sided. Costa of valva slightly convex medially, cucullus very broad, its distal margin medi- 

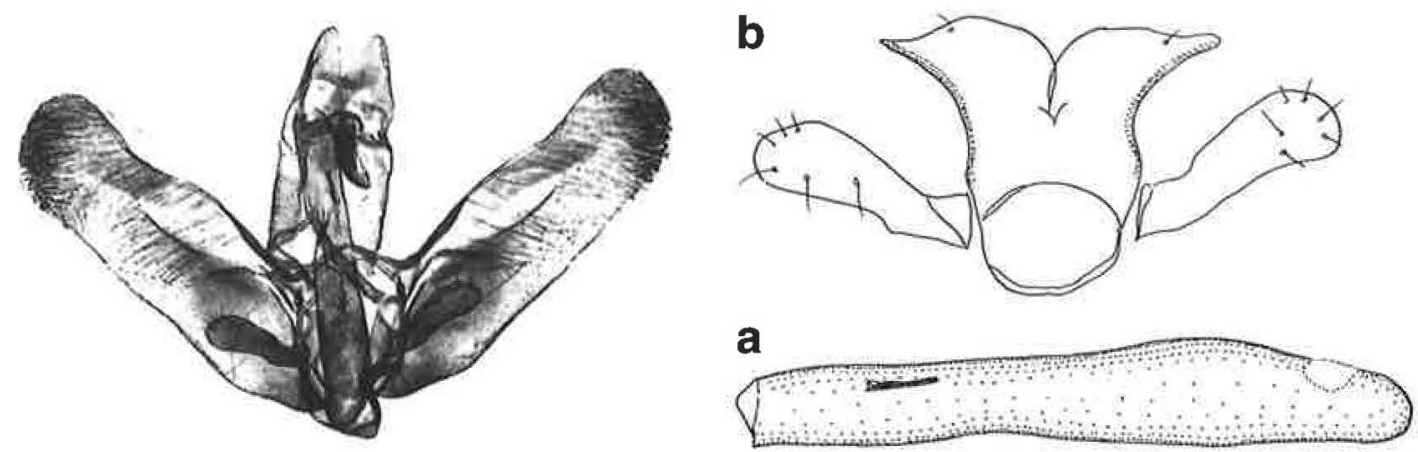

Fig. 6. Male genitalia of Elachista ripula sp. n. holotype (LK 1367). - a: Aedeagus. - b: Juxta and digitate process.

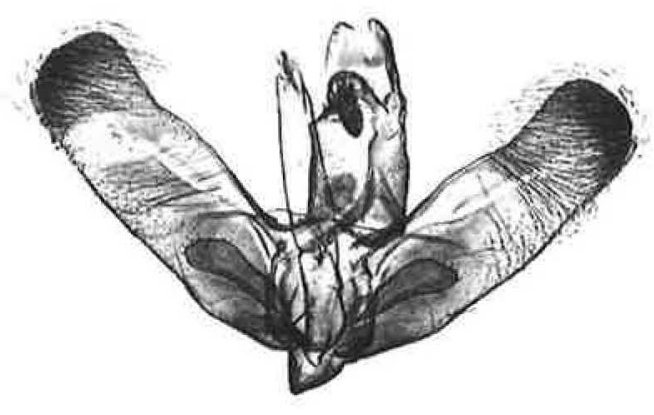

b

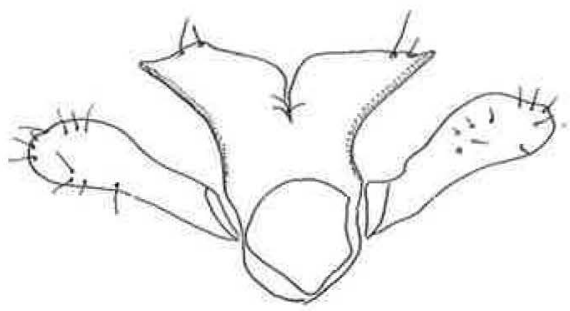

a

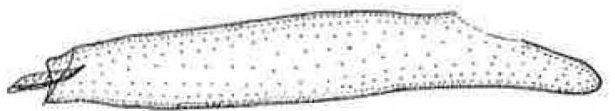

Fig. 7. Male genitalia of Elachista ripula sp. n. paratype (LK 1211). - a: Aedeagus. - b: Juxta and digitate process.

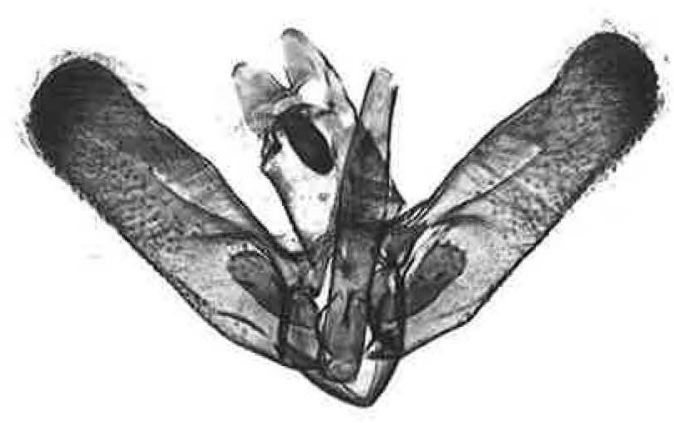

b
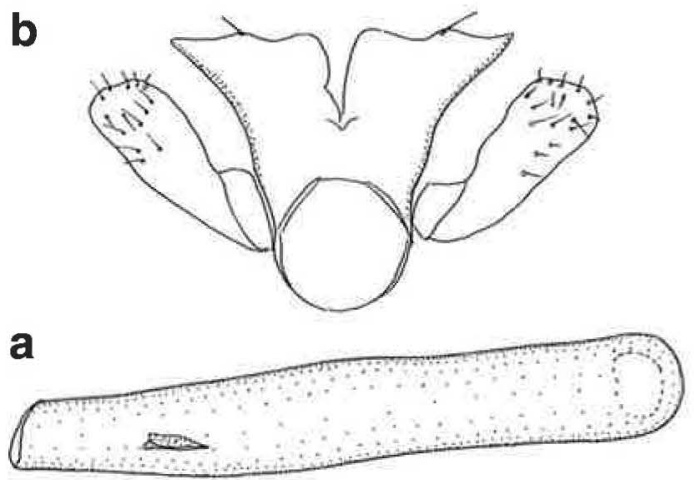

Fig. 8. Male genitalia of Elachista triatomea (Haworth) (Denmark, LK 2173). - a: Aedeagus. - b: Juxta and digitate process.

ally almost straight, sacculus basally convex, distal 2/3 straight. Digitate process long and slender, club-shaped, tip elongate oblique, setose, extending to $1 / 3$ of valva. Juxta lobes laterally distinctly produced, median margin almost straight, distal margin weakly convex medially and laterally, with one or two setae, lateral margin sclerotized, strongly concave. Vinculum short, rounded. Aedeagus long, weakly s-shaped, broadest beyond middle, cornutus small, elongate, almost straight. 
Female genitalia: Papillae anales relatively short, distally rounded, basally weakly sclerotized. Apophyses straight, slender, apophyses posteriores $1.5 \times$ the length of apophyses anteriores. Ostium bursae very small, situated in the middle of broad cup-like hollow formed of anterior margin of sternum 8; no distinct antrum. Colliculum short, with sclerotized band; ductus seminalis arising close to ostium. Ductus bursae long, densely covered with small sclerotized grains, gradually tapering towards corpus bursae. Corpus bursae almost rounded, covered with internal spines; without signum.

Diagnosis. - The new species is closely related to the European E. triatomea Haworth (Figs. $8,8 \mathrm{a}, 8 \mathrm{~b})$, and the Nearctic $E$. orestella (Busck) and $E$. aurocristata Braun (cf. Kaila 1997). It is larger and more distinctly coloured than E. triatomea, resembling $E$. orestella in this respect. In the characteristics of the male genitalia the new species is distinguished from these species as follows: The uncus lobes are distally triangular in $E$. orestella and E. aurocristata, more rounded in $E$. triatomea and $E$. ripula. The valva is narrowest in E. orestella and E. triatomea, broadest in E. aurocristata which also has the cucullus most distinctly produced towards costa. The valva of E. ripula is nearly as broad as in E. aurocristata. The aedeagus is distinctly smaller in $E$. triatomea than in the other species. The digitate process is short both in E. triatomea and E. orestella extending to $1 / 4$ of valva in these species, distinctly longer and distally elongate oblique in E. ripula and E. aurocristata.

Acknowledgements. I thank J. Jalava and J. Kullberg for generously providing their Elachistid materials for identification, as well as S. Koponen and V. Rinne for their help in the search for the Finnish specimen of E. ripula. Tieteellisen Perhostutkimuksen Edistämisrahasto and The Finnish Museum of Natural History made financial contributions to the Ural expedition.

\section{References}

Kaila, L. 1997: A revision of the Nearctic species of Elachista s. 1. II. The argentella group (Lepidoptera, Elachistidae). - Acta Zool. Fennica 206: 1-93.

Traugott-Olsen, E. \& Nielsen, E. S. 1977: The Elachistidae (Lepidoptera) of Fennoscandia and Denmark. - Fauna Entomol. Scand. 6. 299 pp.

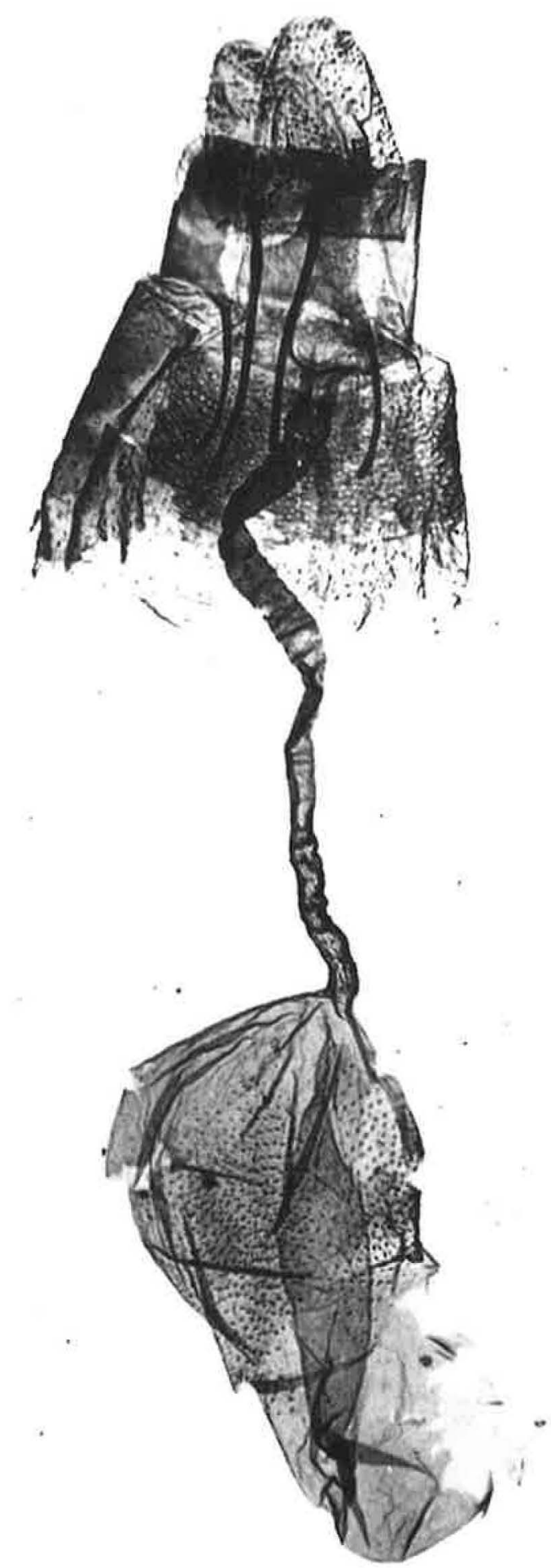

Fig. 9. Female genitalia of Elachista ripula sp. n. paratype (LK 1366). 